\title{
HUBUNGAN MOTIVASI ORANG TUA DENGAN KEBERADAAN TELUR CACING PADA TINJA SISWA DI SDN 1 SUKAWATI KABUPATEN GIANYAR
}

\author{
Anak Agung Ary Dwiutami ${ }^{1}$; Ni Ketut Rusminingsih²; I Ketut Aryana ${ }^{3}$
}

\begin{abstract}
Bali province is one of provinces in Indonesia whose community especially children aged 5-12 years who still have intestinal worms infection with varying prevalence. This research is done in order to know the relationship of parents' motivation with the existence of worm eggs in the stools of students at SDN 1 Sukawati. This research is an analytical survey with cross sectional study design. The number of samples from this study are 67 respondents and 67 samples of stool students. Statistical test analysis in this study using Chi Square analysis method $\left(X^{2}\right)$. Characteristics of respondents obtained the dominant of age parents and students are between 38-43 years (52\%) and students between 9-11 years (48\%). The dominant of parents' education and the sex of the students are senior high school (47\%) and female (52\%). The relationship of parents' motivation with the existence of worm eggs in the stools of students is undefined because the existence of worm eggs in stool students is constant or all (100\%) of samples stool are negative worm eggs. Various factors other than motivation can influence it. Nevertheless, parents should still motivate students to prevent intestinal worms because the disease can be infected at any time.
\end{abstract}

Keywords: worms infection, parents' motivation, elementary school students

Keluarga memiliki peran utama dalam pembentukan karakter dan kepribadian anak terutama orang tua. Orang tualah yang paling mengenal kapan dan dengan cara bagaimana anak belajar sebaikbaiknya (1)(Irianto K, 2014) Namun, banyak orang tua yang kurang memperhatikan kebersamaan dengan anak sehingga kurang meluangkan waktu bagi anak-anak mereka untuk membangun komunikasi yang baik dan efektif. Wujud komunikasi yang baik antara orangtua dan anak adalah dengan memberikan motivasi kepada anak. Motivasi merupakan unsur psikologis yang penting dalam kehidupan manusia (2)(Ningtyas,2015) Orang tua mempunyai peranan penting dalam membina motivasi terhadap anak salah satunya dalam pencegahan penyakit.

Di Indonesia masih banyak penyakit yang merupakn masalah kesehatan, salah satunya cacingan. WHO menyatakan bahwa disamping penyakit malaria, lebih dari separuh kesakitan penduduk di negara berkembang disebabkan oleh infeksi parasitik cacing(3)(P2PL D.J,.2012). Cacingan merupakan penyakit yang banyak ditemukan pada anak usia sekolah dasar. Hal tersebut karena golongan umur ini yang sering berhubungan dengan tanah (2)(Fitri,Saam, \& Hamidy,2012). Hasil survei di beberapa provinsi di Indonesia menunjukkan prevalensi infeksi cacingan antara 60\%-80\% pada anak usia sekolah dasar (4)(Umar,2008). Penyakit cacing 
usus yang ditularkan melalui tanah disebut Soil Transmitted Helminths/STH .(5)(Fitri,Saam, \& Hamidy,2012).

Provinsi Bali merupakan salah satu provinsi yang masyarakatnya terutama anak usia 5-12 tahun yang masih mengalami infeksi cacing usus. Prevalensi infeksi cacing usus di Bali bervariasi dari $57 \%$ sampai $82 \%$ untuk Ascaris lumbricoides, $21 \%$ sampai $86 \%$ untuk Trichuris trichiura, dan $9 \%$ sampai $64 \%$ untuk cacing tambang (6)(Ghassani, 2011). Mengingat bahwa cacingan merupakan salah satu penyakit yang berbasis lingkungan maka perhatian terhadap sanitasi lingkungan perlu ditingkatkan salah satunya di Kabupaten Gianyar. Hal ini penting karena menurut data Dinas Kesehatan Provinsi Bali tahun 2015 Kabupaten Gianyar menempati urutan ketiga terendah untuk desa yang telah melaksanakan Sanitasi Total Berbasis Masyarakat (STBM) dengan presentase $58,57 \%$.

Salah satu desa di Kabupaten Gianyar adalah desa Sukawati. Desa Sukawati terdiri dari UPT Kesmas Sukawati I dan UPT Kesmas Sukawati II. Berdasarkan data Dinas Kesehatan Kabupaten Gianyar tahun 2014 sarana air bersih yang digunakan dan akses air minum berkualitas di kedua UPT Kesmas Sukawati persentasenya $85,40 \%$ dan $71,85 \%$ masih di bawah rata-rata kabupaten $(87,06 \%)$. Kemudian di tahun berikutnya UPT Kesmas Sukawati II persentasenya $(73,32 \%)$ masih berada di bawah rata-rata kabupaten $(82,12 \%)$. Hal ini perlu mendapat perhatian mengingat bahwa air merupakan kebutuhan dasar manusia, air digunakan untuk memasak, mandi dan mencuci pakaian dan keperluan sehari-hari.
Apabila air yang digunakan tidak bersih atau terkontaminasi dengan telur cacing akan menyebabkan timbulnya infeksi cacingan (7)(Ali, Zulkarnaini, \& Affandi, 2016) . Kondisi inilah yang menarik penulis untuk melakukan penelitian dengan tujuan menganalisis hubungan motivasi orang tua dengan keberadaan telur cacing pada tinja siswa di SDN 1 Sukawati Kabupaten Gianyar.

\section{METODE}

Penelitian ini bersifat survei analitik dengan rancangan penelitian cross sectional. Data diperoleh dari sampel melalui angket yang dibagikan kepada responden dan kemudian dihubungkan dengan hasil pemeriksaan laboratorium. Besar sampel sebanyak 67 orang tua dan 67 sampel tinja siswa. Teknik pengambilan sampel yang digunakan adalah probability sampling. Dalam probability sampling, teknik yang digunakan adalah simple random sampling. Penggunaan teknik ini dikarenakan setiap unsur dalam populasi mempunyai kesempatan yang sama untuk dipilih dan dijadikan sampel. Pengambilan sampel dilakukan dengan cara membuat gulungan kertas sesuai dengan jumlah siswa pada satu kelas kemudian mengambil secara acak jumlah sampel sesuai perhitungan besar sampel masing-masing kelas (ulangi hingga kelas VI), gulungan kertas yang dipilih kemudian dijadikan sampel. Cara pengumpulan data untuk motivasi orang tua dikumpulkan melalui angket sedangkan untuk keberadaan telur cacing pada tinja siswa, datanya dikumpulkan melalui hasil pemeriksaan laboratorium. Pada analisis bivariat menggunakan 
metode analisis Chi Square $\left(\mathrm{X}^{2}\right)$. Selanjutnya untuk mengetahui besarnya hubungan antar kedua variabel tersebut dilakukan perhitungan Coefficient Contingency. (8)(Sugiyono, 2012)

\section{HASIL DAN PEMBAHASAN}

A. Hasil

1. Karakteristik penelitian

subyek/obyek

a. Usia orang tua Karakteristik orang tua berdasarkan umur diperoleh hasil sebagai berikut:

Tabel 1

Distribusi Frekuensi Berdasarkan Umur Responden/Orang Tua Siswa SDN 1 Sukawati Kabupaten Gianyar

\begin{tabular}{ccc}
\hline $\begin{array}{c}\text { Umu } \\
\mathbf{r}\end{array}$ & $\begin{array}{c}\text { Frekuens } \\
\mathbf{i}\end{array}$ & $\begin{array}{c}\text { Persentas } \\
\mathbf{e}(\boldsymbol{\%})\end{array}$ \\
\hline $32-37$ & 12 & 18 \\
tahun & & \\
$38-43$ & 35 & 52 \\
tahun & & \\
$44-50$ & 20 & 30 \\
tahun & & \\
\hline Total & $\mathbf{6 7}$ & $\mathbf{1 0 0}$ \\
\hline
\end{tabular}

Pada tabel di atas menunjukkan bahwa umur orang tua (responden) di SDN 1 Sukawati terbanyak antara 38-43 tahun dengan jumlah 35 orang $(52 \%)$.

b. Pendidikan orang tua

Karakteristik orang tua berdasarkan pendidikan diperoleh hasil sebagai berikut:
Tabel 2

Distribusi Frekuensi Berdasarkan Tingkat Pendidikan Responden/Orang Tua Siswa SDN 1 Sukawati Kabupaten Gianyar

\begin{tabular}{lcc}
\hline $\begin{array}{c}\text { Pendidik } \\
\text { an }\end{array}$ & $\begin{array}{c}\text { Frekue } \\
\text { nsi }\end{array}$ & $\begin{array}{c}\text { Persent } \\
\text { ase } \mathbf{( \% )}\end{array}$ \\
\hline SLTA & 47 & 70 \\
Akademi & 8 & 12 \\
Perguruan & 12 & 18 \\
Tinggi & & \\
\hline \multicolumn{1}{c}{ Total } & $\mathbf{6 7}$ & $\mathbf{1 0 0}$ \\
\hline
\end{tabular}

Pada tabel di atas menunjukkan bahwa pendidikan orang tua (responden) di SDN 1 Sukawati terbanyak adalah SLTA dengan jumlah 47 orang $(70 \%)$.

c. Usia siswa SDN 1 Sukawati Karakteristik siswa SDN 1 Sukawati berdasarkan umur diperoleh hasil sebagai berikut: Tabel 3

Distribusi Frekuensi Berdasarkan Umur Siswa SDN 1 Sukawati Kabupaten Gianyar

\begin{tabular}{lcc}
\hline $\begin{array}{c}\text { Umu } \\
\mathbf{r}\end{array}$ & $\begin{array}{c}\text { Frekuens } \\
\mathbf{i}\end{array}$ & $\begin{array}{c}\text { Persentas } \\
\mathbf{e}(\boldsymbol{\%})\end{array}$ \\
\hline $6-8$ & 23 & 34 \\
tahun & & \\
$9-11$ & 32 & 48 \\
tahun & & \\
$12-13$ & 12 & 18 \\
tahun & & \\
\hline Total & $\mathbf{6 7}$ & $\mathbf{1 0 0}$ \\
\hline
\end{tabular}

Pada tabel di atas menunjukkan bahwa umur siswa di SDN 1 Sukawati yang terpilih sebagai sampel terbanyak antara 9-11 tahun dengan jumlah 32 siswa $(48 \%)$.

d. Jenis Kelamin siswa SDN 1 Sukawati 
Karakteristik siswa SDN 1 Sukawati berdasarkan jenis kelamin diperoleh hasil sebagai berikut:

Tabel 4

Distribusi Frekuensi Berdasarkan Jenis Kelamin Siswa SDN 1 Sukawati Kabupaten Gianyar

\begin{tabular}{lcc}
\hline $\begin{array}{c}\text { Jenis } \\
\text { Kelamin }\end{array}$ & $\begin{array}{c}\text { Frekuen } \\
\text { si }\end{array}$ & $\begin{array}{c}\text { Persenta } \\
\text { se } \mathbf{( \% )}\end{array}$ \\
\hline Laki-laki & 32 & 48 \\
Perempu & 35 & 52 \\
an & & \\
\hline \multicolumn{1}{c}{ Total } & $\mathbf{6 7}$ & $\mathbf{1 0 0}$ \\
\hline
\end{tabular}

Pada tabel di atas menunjukkan bahwa jenis kelamin siswa di SDN 1 Sukawati yang terpilih sebagai sampel terbanyak adalah perempuan dengan jumlah 35 siswa $(52 \%)$.

\section{Analisis univariat}

a. Bimbingan orang tua kepada siswa SDN 1 Sukawati Kabupaten Gianyar mengenai pencegahan cacingan

Hasil analisis adalah sebagai berikut:

Tabel 5

Distribusi Bimbingan Orang Tua kepada Siswa SDN 1 Sukawati Kabupaten Gianyar mengenai Pencegahan Cacingan

\begin{tabular}{ccc}
\hline $\begin{array}{l}\text { Bimbingan } \\
\text { Pencegahan } \\
\text { Cacingan }\end{array}$ & Frekuensi & $\begin{array}{c}\text { Persentase } \\
(\boldsymbol{\%})\end{array}$ \\
\hline Rendah & 0 & $0 \%$ \\
Cukup & 16 & $24 \%$ \\
Tinggi & 51 & $76 \%$ \\
\hline Total & $\mathbf{6 7}$ & $\mathbf{1 0 0 \%}$ \\
\hline
\end{tabular}

Pada tabel di atas menunjukkan bahwa jumlah responden yang membimbing siswa dalam upaya pencegahan cacingan dengan kategori tinggi sebanyak 51 orang (76\%).

b. Dorongan orang tua kepada siswa SDN 1 Sukawati Kabupaten Gianyar mengenai pencegahan cacingan.

Hasil analisis adalah sebagai berikut:

Tabel 6

Distribusi Dorongan Orang Tua kepada Siswa SDN 1 Sukawati Kabupaten Gianyar mengenai Pencegahan Cacingan

\begin{tabular}{ccc}
\hline $\begin{array}{c}\text { Doronga } \\
\text { n dalam } \\
\text { Pencegah } \\
\text { an }\end{array}$ & $\begin{array}{c}\text { Frekue } \\
\text { nsi }\end{array}$ & $\begin{array}{c}\text { Persent } \\
\text { ase }(\%)\end{array}$ \\
Cacingan & & \\
\hline Rendah & 0 & $0 \%$ \\
Cukup & 2 & $3 \%$ \\
Tinggi & 65 & $97 \%$ \\
\hline Total & $\mathbf{6 7}$ & $\mathbf{1 0 0 \%}$ \\
\hline
\end{tabular}

Pada tabel di atas menunjukkan bahwa jumlah responden yang mendorong siswa dalam upaya pencegahan cacingan dengan kategori tinggi sebanyak 65 orang (97\%).

c. Fasilitas yang disediakan orang tua kepada siswa SDN 1 Sukawati Kabupaten Gianyar dalam rangka pencegahan cacingan

Hasil analisis adalah sebagai berikut: 
Tabel 7

Distribusi Fasilitas yang disediakan Orang Tua kepada

Siswa SDN 1 Sukawati

Kabupaten Gianyar dalam

Rangka Pencegahan Cacingan

\begin{tabular}{ccc}
\hline $\begin{array}{c}\text { Fasilitas } \\
\text { Pencegah } \\
\text { an } \\
\text { Cacingan }\end{array}$ & $\begin{array}{c}\text { Frekue } \\
\text { nsi }\end{array}$ & $\begin{array}{c}\text { Persent } \\
\text { ase }(\%)\end{array}$ \\
\hline Rendah & 3 & $4 \%$ \\
Cukup & 16 & $24 \%$ \\
Tinggi & 48 & $72 \%$ \\
\hline Total & $\mathbf{6 7}$ & $\mathbf{1 0 0 \%}$ \\
\hline
\end{tabular}

Pada tabel di atas menunjukkan bahwa jumlahres ponden yang menyediakan fasilitas untuk siswa dalam upaya pencegahan cacingan dengan kategori tinggi sebanyak 48 orang $(72 \%)$.

d. Motivasi orang tua kepada siswa SDN 1 Sukawati Kabupaten Gianyar mengenai pencegahan cacingan

Hasil analisis adalah sebagai berikut:

Tabel 8

Distribusi Motivasi Orang Tua kepada Siswa SDN 1 Sukawati Kabupaten Gianyar mengenai Pencegahan Cacingan

\begin{tabular}{ccc}
\hline $\begin{array}{c}\text { Motiva } \\
\text { si } \\
\text { Orang } \\
\text { Tua }\end{array}$ & $\begin{array}{c}\text { Frekuen } \\
\text { si }\end{array}$ & $\begin{array}{c}\text { Persenta } \\
\text { se }(\%)\end{array}$ \\
\hline Rendah & 0 & 0 \\
Cukup & 9 & $13 \%$ \\
Tinggi & 58 & $87 \%$ \\
\hline Total & $\mathbf{6 7}$ & $\mathbf{1 0 0 \%}$ \\
\hline
\end{tabular}

Pada tabel di atas menunjukkan bahwa jumlah responden yang memotivasi siswa dalam upaya pencegahan cacingan dengan kategori tinggi sebanyak 58 orang $(87 \%)$.

e. Keberadaan telur cacing pada tinja siswa SDN 1 Sukawati Kabupaten Gianyar Hasil analisis adalah sebagai berikut:

Tabel 9

Distribusi Keberadaan Telur Cacing pada tinja Siswa SDN 1 Sukawati Kabupaten Gianyar

\begin{tabular}{ccc}
\hline $\begin{array}{c}\text { Telur } \\
\text { Cacin } \\
\mathbf{g}\end{array}$ & $\begin{array}{c}\text { Frekuens } \\
\mathbf{i}\end{array}$ & $\begin{array}{c}\text { Persentas } \\
\mathbf{e}(\boldsymbol{\%})\end{array}$ \\
pada & & \\
Tinja & & \\
\hline Ada & 0 & $0 \%$ \\
Tidak & 67 & $100 \%$ \\
Ada & & \\
\hline Total & $\mathbf{6 7}$ & $\mathbf{1 0 0 \%}$ \\
\hline
\end{tabular}

Pada tabel di atas menunjukkan bahwa semua sampel tinja siswa SDN 1 Sukawati yang diperiksa negatif cacingan sebanyak 67 orang $(100 \%)$.

\section{Analisis Bivariat}

Hasil analisis hubungan motivasi orang tua dengan keberadaan telur cacing pada tinja siswa SDN 1 Sukawati Kabupaten Gianyar adalah sebagai berikut: 
Sukawati dominan SLTA dengan jumlah 47 orang $(70 \%)$. Orang tua dengan akhir tamatan SLTA lebih mempunyai wawasan yang luas dibanding mereka yang hanya tamat SLTP. Menurut (12)Setiawan (2014), pengetahuan yang mereka miliki salah satunya akan menuntun anakanak mereka menuju kehidupan yang sehat, karena orangtua telah berlandaskan pada ilmu-ilmu dasar terkait masalah kesehatan yang didapatkan pada pembelajaran di sekolahnya. Selain itu dengan umur dewasa tersebut orang tua mempunyai pengalaman yang lebih dibandingkan mereka yang lebih muda sehingga dapat membimbing anak dengan baik.

Dalam penelitian ini juga diukur setiap indikator dalam motivasi orang tua terhadap anak yang antara lain bimbingan, fasilitas dan dorongan dalam upaya pencegahan cacingan. Berdasarkan hasil penelitian dari 67 orang tua/responden didapatkan responden yang membimbing dan mendorong siswa dalam upaya pencegahan tidak ada yang dalam kategori rendah. Namun, dari 67 orang tua/responden didapatkan responden yang menyediakan fasilitas untuk siswa dalam upaya pencegahan cacingan dalam kategori rendah sebanyak 3 orang (4\%). Dari 67 responden pada indikator menyediakan fasilitas, jawaban tidak pernah dominan pada pertanyaan nomor 16 yang diperoleh 4 orang tua yang menjawab tidak pernah memberikan bekal makanan dan minuman kepada siswa saat pergi ke sekolah.

Anak sekolah umumnya setiap hari menghabiskan sepertiga waktunya di sekolah. Pada tahap ini, anak mendapat peluang yang lebih banyak untuk memperoleh makanan, terutama yang diperolehnya di luar rumah sebagai makanan jajanan. Mereka memiliki kebebasan untuk menggunakan uang jajan mereka untuk makanan dan minuman sesuai dengan selera mereka sendiri.Ketersediaan makanan di tempat-tempat umum memungkinkan anak untuk lebih banyak mengkonsumsi makanan jajana. (13)(Putra, 2009)

Sekolah Dasar Negeri 1

Sukawati merupakan sekolah yang berlokasi di dekat pasar dan berbagai macam warung yang menjajakan makanan jajanan serta tidak jarang pedagang kaki lima berjualan di depan sekolah. Makanan jajanan yang ditawarkan belum tentu menyehatkan, karena kebanyakan dari penjual makanan jajanan belum sepenuhnya memperhatikan kebersihan, keamanan dan kandungan gizi makanan yang dijajakan(13) (Putra,2009). Dengan memberikan bekal makanan dan minuman dari rumah tentu akan sangat bermanfaat dalam memutuskan rantai penularan penyakit khususnya cacingan akibat makanan dan minuman yang dikhawatirkan tidak dijaga sanitasinya.

Berkaitan dengan penelitian ini, maka peneliti berpendapat bahwa semakin baik motivasi orang tua dalam memotivasi anak terutama dalam hal pencegahan cacingan maka akan semakin baik pula anak dalam menerapkan kebiasaan untuk menghindari infeksi cacingan.

2. Penyakit cacingan pada siswa SDN 1 Sukawati Kabupaten Gianyar

Berdasarkan hasil penelitian dari 67 siswa SDN 1 Sukawati didapatkan semua (100\%) sampel tinja siswa yang diperiksa negatif cacingan. Hasil tersebut sejalan 
dengan hasil kuesioner yaitu pada indikator membimbing dan mendorong siswa dalam upaya pencegahan cacingan, tidak ada yang dalam kategori rendah sehingga lingkungan tempat berinteraksi siswa tidak terkontaminasi telur cacing. Namun demikian, tetap diperlukan upaya pencegahan agar nantinya tetap tidak terjadi infeksi cacingan di lokasi tersebut.

Menurut (10)Koes Irianto (2009) cacingan merupakan masalah kesehatan yang perlu penanganan khusus, terutama di daerah tropis karena cukup banyak penduduk menderita cacingan.Dalam penelitian ini, penulis berfokus pada Soil Transmitted Helminths (STH), yaitu sekelompok cacing nematode yang menyebabkan infeksi melalui telur atau cacing yang berada di tanah. Cacing yang dimaksud antara lain Ascaris lumbricoides, Trichuris trchiura dan Cacing tambang (Necator americanus dan Ancylostoma duodenale) yang merupakan cacing STH yang paling sering menyebabkan infeksi pada manusia.

Penularan umumnya terjadi melalui makanan, minuman, dan mainan dengan perantara tangan yang terkontaminasi telur yang sedang infektif.Infeksi sering terjadi pada anak daripada orang dewasa.Hal ini disebabkan karena anak sering berhubungan dengan tanah yang merupakan tempat berkembangnya telur cacing. Infeksi terjadi karena menelan telur yang telah berembrio melalui tangan, makanan atau minuman yang telah terkontaminasi langsung melalui debu, hewan rumah atau mainan. Diperoleh juga laporan bahwa dengan adanya usaha untuk meningkatkan kesuburan tanaman sayuran dengan mempergunakan feses manusia menyebabkan sayuran merupakan sumber infeksi daric acing tersebut. Selain itu, penyebarannya juga disebabkan oleh pembuangan kotoran orang-orang yang terinfeksi di tempat-tempat yang dilewati orang lain, tanah atau pasir tempat pembuangan kotoran yang merupakan medium baik bagi larva, suhu panas dan lembab serta populasi yang miskin dengan orang-orang tanpa sepatu atau alas kaki. (10)Koes Irianto (2009)

Untuk mencegah cacingan maka menjaga kebersihan tubuh dan lingkungan merupakan hal yang penting.Penggunaan obat cacingan hanya diperlukan, apabila telah dipastikan adanya infeksi cacing dan tidak dianjurkan digunakan secara rutin tanpa pemeriksaan laboratorium klinis terlebih dahulu. Kebiasaan hidup bersih dan sehat inilah yang tidak serta merta muncul begitu saja. Perlu adanya campur tangan dari berbagai pihak salah satunya orang tua. Siswa merupakan seorang anak yang telah dibesarkan dalam sebuah keluarga, terlahir dalam sebuah keluarga, dan dibesarkan oleh orang tuanya. Siswa mempunyai keinginankeinginan untuk melakukan sesuatu dan orang tua yang mendorongnya (11)(Ernanto, 2014)

Dengan demikian bimbingan, dorongan dan fasilitas dari orang tua dalam upaya pencegahan cacingan tetap diharapkan demi menjaga agar siswa tetap tidak terinfeksi telur cacing kedepannya.

3. Hubungan motivasi orang tua dengan keberadaan telur cacing pada tinja siswa di SDN 1 Sukawati Kabupaten Gianyar.

Berdasarkan hasil penelitian diketahui hasil uji chi-square untuk hubungan motivasi orang tua dengan 
keberadaan telur cacing pada tinja siswa SDN 1 Sukawati Kabupaten Gianyar tidak terdefinisi/undefined. Hal tersebut terjadi karena keberadaan telur cacing pada tinja siswa nilainya konstan atau semua (100\%) sampel tinja negatif cacingan.Dengan demikian, peneliti berpendapat meskipun pada tahun 2015 Sukawati merupakan salah satu desa dengan sarana air bersih yang digunakan dan akses air minum berkualitas masih di bawah rata-rata kabupaten, tidak serta merta menyebabkan infeksi cacingan mudah tersebar.

Namun, sejalan dengan hasil kuesioner yaitu tidak ada motivasi orang tua dalam kategori rendah maka tidak diragukan seluruh siswa tidak ada yang terjangkit penyakit cacingan. Namun demikian, dari 67 responden diperoleh 9 orangtua dengan kategori motivasi cukup. Dari 9 responden dengan kategori cukup tersebut diketahui pertanyaan kuesioner dengan nilai terendah adalah pertanyaan nomor 26 . Tiga orang responden menjawab tidak pernah dan 6 orang menjawab kadang-kadang dalam memberikan hukuman/sangsi ketika siswa melakukan aktifitas yang memungkinkan terjadinya infeksi cacingan.

Hukuman/ sanksi yang bersifat mendidik apabila selalu dilakukan maka perilaku anak akan semakin baik khususnya dalam upaya pencegahan cacingan. Sanksi mendidik yang dimaksud yaitu yang berkaitan secara logis dengan perilaku salah, tidak terlalu lama (karena 5-10 menit sama dengan setengah jam bagi siswa), prosedur sanksi hendaknya membantu memahami dan memperkuat komitmen untuk berperilaku yang lebih baik dan tidak berlebihan (14) (Nahuda, et al., 2007). Misalnya orang tua menegur tindakan anak yang salah dan memberikan penjelasan kepada anak mengapa hal tersebut salah serta menunjukkan hal yang benar. Orang tua memiliki kewajiban untuk mengontrol perilaku anak melakukan kesalahan.

Meskipun diperoleh 9 orangtua dengan kategori motivasi yang cukup akan tetapi infeksi cacingan tidak ada yang terjadi maka berbagai faktor selain motivasi juga dapat mempengaruhi hal tersebut. Faktor yang dimaksud seperti pengetahuan, niat, persepsi, pengalaman, sikap, keyakinan, keinginan, sosio-budayadi lingkungan anak itu sendiri.

Tingkat pengetahuan seorang anak akan mempengaruhi perilakunya. Semakin banyak pengetahuan dan pengalaman yang dimilikinya tentang perilaku yang berkaitan dengan sehat-sakit maka semakin mampu anak tersebut menjaga dirinya sendiri tanpa adanya dorongan dari luar. Motivasi juga dapat muncul dari dalam dirinya sendiri. Selain itu, niat anak serta dukungan sosial dari masyarakat sekitarnya serta ada atau tidak adanya informasi tentang kesehatan atau fasilitas kesehatan dapat mempengaruhi perilaku anak dalam upaya pencegahan penyakit.

\section{SIMPULAN DAN SARAN}

\section{A. Kesimpulan}

Berdasarkan penelitian yang telah dilakukan, maka dapat disimpulkan sebagai berikut:

1. Dari 67 orang tua/responden didapatkan responden yang memotivasi siswa dalam upaya pencegahan cacingan dengan kategori tinggi sebanyak 58 orang 
(87\%), cukup 9 orang (13\%) dan yang rendah tidak ada.

2. Dari 67 siswa SDN 1 Sukawati didapatkan semua (100\%) sampel tinja siswa yang diperiksa negatif cacingan.

3. Hubungan motivasi orang tua dengan keberadaan telur cacing pada tinja siswa SDN 1 Sukawati Kabupaten Gianyar tidak terdefinisi/undefined karena keberadaan telur cacing pada tinja siswa nilainya konstan atau semua (100\%) sampel tinja negatif cacingan.

\section{B. Saran}

Mengacu pada simpulan yang telah dikemukakan, adapun saran yang diajukan sehingga dapat dijadikan bahan pertimbangan yaitu

1. Kepada orang tua sebaiknya lebih memotivasi siswa dalam upaya pencegahan kejadian cacingan terutama dalam menyediakan fasilitas yang berkaitan dengan upaya tersebut.

2. Kepada peneliti selanjutnya sebaiknya memilih lokasi penelitian yang menempati urutan pertama daerah dengan STBM yang rendah serta lokasi yang lebih memungkinkan adanya siswa yang terjangkit cacingan baik itu karena kebutuhan air bersih yang kurang dan penyebab lainnya sehingga hasil penelitian tidak konstan. Selain itu, pembagian kuesioner kepada orang tua sebaiknya langsung dilakukan oleh peneliti dan tidak menitipkan kepada siswa.

\section{DAFTAR PUSTAKA}

1. Irianto K. Parasitologi (Berbagai Penyakit yang Mempengaruhi Kesehatan Manusia). Bandung: CV.YRAMA WIDYA; 2009.

2. Ningtyas WR. Pengaruh Motivasi Orangtua terhadap Prestasi Belajar Matematika Siswa Kelas V SD Negeri 01 Malangjiwan Tahun Pelajaran 2014/2015. Surakarta; 2015.

3. P2PL DJ. Pedoman Pengendalian Kecacingan. Jakarta: TP; 2012.

4. Umar Z. Perilaku Cuci Tangan Sebelum Makan dan Kecacingan pada Murid SD di Kabupaten Pesisir Selatan Sumatera Barat. Sumatera Barat. J Kesehat Masy Nas. 2008; Vol. 2, No.

5. Fitri, J., Saam, Z., \& Hamidy MY Analisis Faktor-Faktor Risiko Infeksi Kecacingan Murid Sekolah Dasar di Kecamatan Angkola Timur Kabupaten Tapanuli Selatan Tahun 2012. Tapanuli: Jurnal IImu Lingkungan. J Ilmu Lingkung. 2012;146-61.

6. Ghassani A. Hubungan Infeksi Cacing Usus STH dengan Kebiasan Bermain Tanah pada SDN 09 Pagi Paseban Tahun 2010. Jakarta; 2011.

7. Ali, R. U., Zulkarnaini, \& Affandi D. Hubungan Personal Hygiene dan Sanitasi Lingkungan dengan Angka Kejadian Kecacingan (Soil Transmitted Helminth) pada 
Petani Sayur di Kelurahan Maharatu Kecamatan Marpoyan Kota Pekanbaru. Pekanbaru: Dinamika Lingkungan Indonesia, Kesehat lingkun. 2016;Vol.3 No.1:24-32.

8. Sayono. Infeksi Cacing Usus yang Ditularkan melalui Tanah pada Anak Sekolah Dasar di Perkotaan dan Pedesaan di Wilayah Kerja Puskesmas Ungaran I. Ungaran. J UNIMUS. 2003;1.

9. Notoatmodjo S. Promosi Kesehatan dan Perilaku Kesehatan. Jakarta: Rineka Cipta; 2012.

10. Irianto K. Ilmu Kesehatan Anak. Bandung: Alfabeta; 2014.

11. Ernanto. Pengaruh Motivasi Orang Tua Terhadap Minat Baca Anak di SD Negeri Wiyoro Bantul. Yogyakarta: Skripsi Program Studi Ilmu Perpustakaan Fakultas Adab dan Ilmu Budaya Universitas Islam Negeri Sunan Kalijaga. Yogyakarta; 2014.

12. Setiawan. Peran Orang Tua dalam Memotivasi Anak Mencuci Tangan dengan Benar dan Memakai Sabun pada Anak Usia Pra Sekolah di TK Aisyiyah Blimbing. Surakarta; 2014.

13. Putra. GAMBARAN KEBIASAAN JAJAN SISWA DI SEKOLAH (Studi di Sekolah Dasar Hj. Isriati Semarang). Semarang; 2009.

14. Nahuda P. et. al. Pencegahan Kekerasan terhadap Anak di Lingkungan Pendidikan. Jakarta: Pusat Pelayanan Terpadu Pemberdayaan Perempuan dan
Anak (P2TP2A) Prov. DKI Jakarta; 2007. 